\title{
Formation of the Aerogas Situation in a Working Face while Mining Callows with Top Coal Caving onto Conveyor
}

\author{
Leonid Shevchenko ${ }^{1}$, Vera Zubareva ${ }^{1}$, and Yevgeny Buryakov ${ }^{2}$ \\ ${ }^{1}$ T.F. Gorbachev Kuzbass State Technical University, 28 Vesennya st., Kemerovo, the Russian \\ Federation \\ ${ }^{2}$ Innovative Eurasian University, 45 Lomova st., Pavlodar, the Republic of Kazakhstan
}

\begin{abstract}
The processes of gas emission into the working face from coal, cut by the mining machine with the simultaneous top coal caving onto the conveyor located behind the powered support units, are considered. The presence of two methane emission sources in the face requires additional measures to ensure the aerologic safety of mining. Given the high rate of mining operations due to the performance of modern cutting machines, there is a problem of maintaining the methane concentration in the upcast at a level of $1 \%$. In this case, gas released from the coal mass caved onto the rear conveyor is partially added to the volume of gas released from the cut coal into the face, which generally increases the absolute gas content in the stope. Measures are proposed to contain the growth of gas content in the face in the form of alternations of machined coal breaking and top coal caving processes, which do not overlap in time during the entire mining cycle. Due to the fact that this technology is experimental, its adaptation to mining and geological conditions of mines is required.
\end{abstract}

\section{Introduction}

The Kuznetsk coal basin is characterized by a wide variety of geological conditions of the occurrence of coal seams of different thicknesses and incidence angles, as well as a wide range of fossil coal grades. This determined the presence of various - more than ten - coal mining systems for each district of Kuzbass. Over time, a number of mining systems stopped to be used due to technical, economic, and security reasons. To date, underground mining of steeply sloping seams in Prokopyevsky-Kiselevsky, Anzhersky and Kemerovsky districts of Kuzbass has been completely stopped and coal is mainly mined from flat seams, where it is possible to introduce high-performance new generation cutting-and-loading machines. These are mainly Leninsky, Belovsky, Kemerovsky and Tomusinsky districts of Kuzbass.

As a rule, in mines where flat seams are mined, one, or rarely two working faces are in operation at a time; however, their productivity is several times higher than the production volumes of previously closed mines. However, there are also problems associated with mining of coal seams with thickness over five meters. Essentially, longwall slicing is known in Kuzbass. The most characteristic in this respect were the Tomusinsky district 
mines, where seams were mined in two or even three slices in a descending order by longwall retreating on each slice's strike starting from the hanging wall. Studies conducted by the Kuzbass Polytechnic Institute in the 80s of the previous century (since 1993 KuzGTU) on the gas content of each slice showed that it is distributed extremely unevenly and decreases with each slice, while the ratio of the average gas content of the first and last slices is from 1.6 to 2.75 . This is due to the fact that during mining of each slice there is an additional natural degassing of the unrecoverable part of the coal seam, which affects the gas balance of the stope. The third slice having been mined; this process is conducted twice $[1,2]$.

Along the way, it should be noted that when mining thick steeply sloping seams in Prokopyevsky-Kiselevsky district of Kuzbass in three or four slices with filling of worked out space, the ratio of gas content of the first and last slices was even higher and reached 6.5 [3, 4].

\section{Materials and Methods}

Returning to flat seam slicing, we note that mining of each slice in time and economic costs can be considered as mining of a separate seam in the same block boundaries with repeated development works for each slice and all the ensuing consequences.

In this regard, at the beginning of the $2000 \mathrm{~s}$, at the Olzheraskaya-Novaya mine of "Southern Kuzbass" JSC, full capacity mining of the seam 21 with the PRC-made ZF$8000 / 22 / 35$ mining machine of chock-shield type along the lower slice and simultaneous top slice caving onto rear conveyor (Fig. 1) started [5, 6, 7, 8]. The complex includes: ZF8000/22/35 powered support, MG-400/930-WD cutter-loader, SGZ-800/800 armoured face conveyor, SGZ-800/800 rear conveyor, SZZ-1000/400 type elevator, PCM 250 crusher.

Coal is fed to the rear conveyor by setting the angle of inclination of the rear shield canopy to the horizon. When setting the rear shield canopy at an angle of $45^{\circ}$ to the horizon, $50 \%$ of the caved coal fell onto the rear conveyor. With a decrease in the angle of inclination of the rear shield canopy, the proportion of coal loaded to the rear conveyor decreased and vice versa. It is quite obvious that in this case the air and gas situation radically differed from the typical conditions of machined mining of medium-thickness seams. The appearance of two of gas emission sources into the working face and the void space caused an increase in the total gas content of the stope on the one hand and created an uneven character of methane production on the other.

The main gas emission source was the coal broken down by the mining machine into the face and the caved top coal blocks of the mined slice after advancing the support units.

The total amount of coal cut in this case far exceeded its mass, which is formed in the working face with the usual technology of machined mining of coal seams. However, if the gas released from the coal cut by the mining machine entered the ventilation stream passing along the face relatively uniformly as the conveyor was loaded, then gas from the caved top coal mass was concentrated in large volumes in very short periods of time and partially penetrated into the working face, creating in it periodic surges of absolute gas content and, accordingly, methane concentration in the upcast.

If we consider these sources separately, we can see that in the face, the volume of methane released from the cut coal depends on the position of the mining machine in the face and, therefore, on the coal mass on the rear conveyor, which monotonously increases as it is loaded [9-15]. 


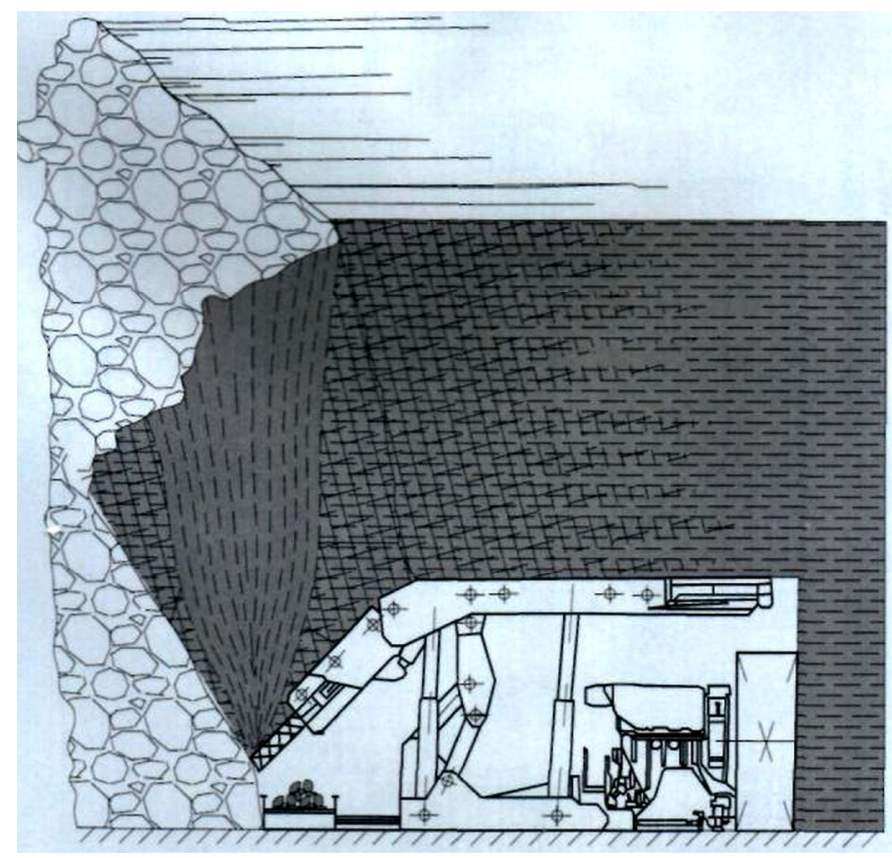

Fig. 1. The longwall top coal caving scheme.

In this case, the volume of methane entering the working face from under the mining machine will be determined from the expression:

$$
\mathrm{I}=\mathrm{M}_{\mathrm{o}} \cdot l_{\mathrm{K}}\left(\mathrm{X}_{\mathrm{o}}-\mathrm{X}_{1}\right)
$$

where $\mathrm{M}_{\mathrm{o}}$ - coal weight per $1 \mathrm{~m}$ of conveyor, $\mathrm{t} ; l_{\kappa}$ - length of the loaded part of the face conveyor, $m ; X_{o}-$ coal seam gas content in the bottomhole zone, $\mathrm{m}^{3} / \mathrm{t} ; \mathrm{X}_{1}-$ residual gas content of coal at the gatehead, $\mathrm{m}^{3} / \mathrm{t}$.

The volume of gas released from the coal entering the caving zone is determined by its mass in the caved cantilever part of the top coal slice after advamcing a group of powered support units. In this case, approximately the same mass of coal falls onto the rear conveyor with a constant difference between the initial and residual gas content. This is due to the fact caving occurs when advancing a constant number of support units at the same time intervals. The volume of methane released during each caving, in this case, can be determined from the expression:

$$
\mathrm{I}=\mathrm{M}_{2} \cdot l \cdot \mathrm{d} \cdot\left(\mathrm{X}_{\mathrm{n}}-\mathrm{X}_{1}\right)
$$

where $\mathrm{M}_{2}$ - top coal thickness, $\mathrm{m} ; l$ - length of the caving section, determined by the total width of the simultaneously advanced support units, $\mathrm{m}$; $\mathrm{d}$ - caving increment, $\mathrm{m} ; \mathrm{X}_{\mathrm{n}}$ - top coal gas content, $\mathrm{m}^{3} / \mathrm{t} ; \mathrm{X}_{1}$-residual gas content of caved coal at the gatehead, $\mathrm{m}^{3} / \mathrm{t}$.

The volumes of methane released both into the working face and into the worked out space are not isolated from each other and, as a rule, have the possibility of partial mixing through openings in the support units in different ratios, which allows considering them as a whole. 


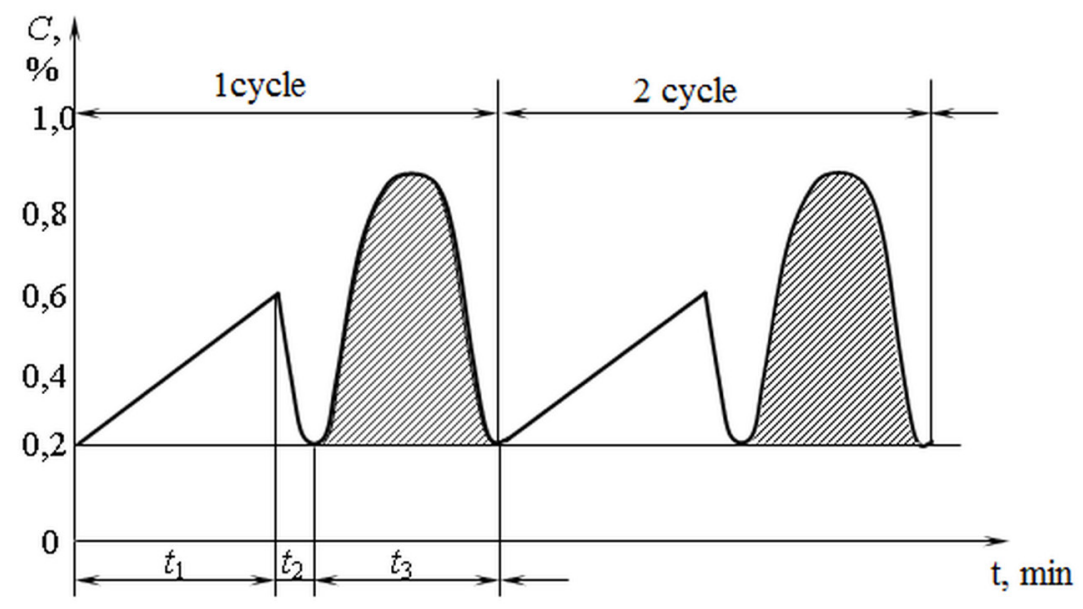

Fig. 2. The changes in methane concentration in the upcast during cyclic mining of the seam 21 with top slice caving onto rear conveyor: $t_{1}$ is the time of the mining machine operation in the cutting-out stope, $t_{2}$ is the time of coal drawing from the face conveyor after stopping the mining machine, $t_{3}$ is the time of increased gas emission from caved top coal. The number of cycles depends on the face length.

\section{Results and Discussion}

In order to avoid complications of the air and gas situation in the face, the processes of machined coal mining the top coal caving are separated in time. In particular, when advancing the support, the work of the mining machine stops, and cut coal on the face conveyor is drawn off. After caving the top coal overhanging console, the work of the mining machine is resumed. Thus, gas emission from two sources does not coincide in time (Fig. 2).

The face ventilation in this case was carried out as follows. The air movement was distributed into two streams: one stream moved along the cutting-out stope, the second - behind the support units in the direction to the air gate. In the upper part of the face, the air flow was divided into two. One moved along the air gate, the second - along the gas drain gate, driven parallel to the air gate. The ratio of air flows in these two directions depends on the aerodynamic resistance in the caved rocks behind the support and is $30 \%$ of the total volume of air supplied to the face in the gas drain gate and $70 \%$ in the air gate.

One more issue arises of calculating the amount of air needed to ventilate the working face with this technology as a whole. The existing Guidelines for the mine ventilation design of 1989 are not quite suitable in this situation; however, some of its provisions can be used in design, but with the obligatory specification of indicators determined empirically in specific conditions, including formulas (1) and (2). The difficulty in this case lies in the fact that the gas content fluctuations are cyclical, and the amount of air supplied to the face due to mine depression is relatively constant. Therefore, in the basic formula for calculating the amount of air, it is very important to correctly calculate the coefficient of non-uniformity of the methane flow rate in the face, and in general, this technique should be approved by the chief engineer of the mine or the territorial department of the Federal Service for Environmental, Technological and Nuclear Supervision of the Russian Federation. 


\section{Conclusion}

Taking into account the fact that the considered longwall top coal caving technology is experimental in Kuzbass and requires improvements in both technological and air-and-gas respects, this article outlines only general approaches to ensuring aerological safety in its implementation. In general, this version of the mining system should be considered promising at least because it provides the full seam stoping, although its application requires a more detailed justification of geological conditions of the occurrence of coal seams, the strength of the host rocks of the roof, the optimal length of the face and the caved top coal thickness of the mined seam, as well as ensuring the quality of coal fed to the rear conveyor.

In addition, when mining coal seams prone to spontaneous combustion, it is necessary to additionally plan measures to prevent endogenous fires, the probability of which with this technology can be quite high. For this purpose, it is necessary to continuously monitor endogenous fire hazard by analyzing the composition of the mine atmosphere for the content of indicator gases, relative humidity and air temperature.

\section{References}

1. L.A. Shevchenko, Methane release particularities when slicing thick coal seams in (Central Research Institute of Economy, Scientific, and Technical Information of the Coal Industry, Moscow, 1987)

2. L.A. Shevchenko, V.I. Purtov, Coal, 1, 5-7 (1988)

3. L.A. Shevchenko, Methane release control when mining thick coal seams in Kuzbass (Kemerovo Book Publishing House, Kemerovo, 1988)

4. L.A. Shevchenko, Industrial Labor Safety, 8, 39-40 (2003)

5. S.I. Kalinin, S.A. Novoseltsev, P.Kh. Galimardanov, A.A. Renev, K.A. Filimonov, A.M. Timoshenko, A.P. Fedorovich, Machine mining of thick seams with top coal caving (Kemerovo Book Publishing House, Kemerovo, 2011)

6. L.N. Gapanovich, A.V. Braitsev, L.Ya. Lavrukhina, Coal, 6, 12-15 (1987)

7. IA. Shundulidi, S.I. Kalinin, A.S. Markov, I.B. Korzhov, P.V. Yegorov, Unconventional and intensive mining technologies (NKBP, Novokuznetsk, 1999)

8. I.A. Shundulidi, S.I. Kalinin, P.V. Yegorov, V.I. Khramtsov, Improvement of technologies of mining thick seams of Olzheraskaya-Novaya deposit (Kemerovo Book Publishing House, Kemerovo, 2001)

9. L.A. Shevchenko, V.A. Zubareva, Bulletin of KuzSTU, 3, 50-55 (2018)

10. V.A. Kovalev, V.N. Puzyrev, Mine aerology (KuzSTU Pub., Kemerovo, 2013)

11. K.S. Kolikov, Mining informational and analytical bulletin, 6, 76 (2017)

12. G.D. Buyalich, B.A. Aleksandrov, Y.A. Antonov, V.V. Voyevodin, Journal of Mining Science, 36(5), 487-492 (2000)

13. Mine ventilation manual (Nedra, Moscow, 1977)

14. G. Buyalich, K. Buyalich, M. Byakov, E3S Web Conf., 21, 03018 (2017)

15. N.O. Kaledina, S.S. Kobylkin, O.S. Kaledin, A.S. Kobulkin, Mine ventilation design textbook (Mining Book, Moscow, 2016) 